\title{
DETERMINATION OF ATMOSPHERIC MERCURY DURING THE NORTH SEA EXPERIMENT
}

\author{
M. LEERMAKERS', W. BAEYENS', \\ R. EBINGHAUS', J. KUBALLA' ${ }^{2}$ and H. H. KOCK ${ }^{2}$ \\ I Department of Analytical Chemistri. Free University of Brussels. Belgium. \\ 2 Institute of Chemistry: GKSS Research Center Geesthacht. Germany
}

\begin{abstract}
Total gaseous mercury (TGM) and rainwater were collected on board of two rescarch vessels (F. S. ALKOR and R.V. BELGICA) positioned $200 \mathrm{~km}$ apart in the center of the North Sea during the North Sea Experiment. September 1991. On the F. S. ALKOR (up-wind ship) TGM concentrations ranged from 0.7 to 2.6 $\mathrm{ng} \cdot \mathrm{m}^{-1}$ with an average of $1.5 \mathrm{ng} \cdot \mathrm{m}^{-1}$ and on the R. V. BELGICA (down-wind ship) TGM ranged from 0.7 to $1.9 \mathrm{ng} \mathrm{m}^{-1}$ with an average of $1.2 \mathrm{ng} \cdot \mathrm{m}^{-3}$. An average $20 \%$ decrease is observed from the up-wind to the downwind ship. which may largely be affected by entrainment into the free troposphere. An overall removal (entrainment) velocity of $0.95 \mathrm{~cm} \cdot \mathrm{s}^{-1}$ was calculated for the whole experiment. The average removal velocity was $0.5 \mathrm{~cm} \cdot \mathrm{s}^{-1}$ for dry periods and varied between 1 to $5 \mathrm{~cm} \cdot \mathrm{s}^{-1}$ during rain events. Rainwater concentrations varied between 5 and $25 \mathrm{ng} \cdot l^{-1}$. Based on these data an annual wet deposition flux of $1.08 \mathrm{ng} \mathrm{Hg} \mathrm{cm}^{-2} \mathrm{yr}^{1 \cdot}$ was estimated for the North Sea.
\end{abstract}

keywords: mercury, atmosphere. rainwater, marine

\section{Introduction}

The North Sea Experiment (NOSE 1991) was carried out from September 15 to 27 , 1991 as part of the EUROTRAC "Air-Sea Exchange (ASE)" project. The North Sea is a relatively enclosed body of water receiving inputs from large areas of industrialized Northern Europe. Due to its location and economic significance, there is much international concern over pollutant inputs to the North Sea. There is strong evidence that atmospheric pollutants emitted over Europe, are significantly removed into regional and coastal waters. For many pollutants, atmospheric deposition provides a major input pathway, in some cases exceeding inputs from rivers and direct coastal discharges. In order to measure changes in concentrations of trace metals, sulfur- and nitrogen compounds in air and precipitation in a moving air mass (Lagrangian experiment), samples were collected on board of two research vessels arranged to lie $200 \mathrm{~km}$ apart, aligned in wind and along airparcel forward trajectories. In a Lagrangian experiment the same air mass parcel is sampled at different time intervals. Variations in concentrations of a given component during transport are thus either due to internal processes (such as oxidation or adsorption on particles) or external processes such as sources or sinks. Whereas over land anthropogenic activities represent a variety of atmospheric emission sources, over sea only natural emission sources, which are much more homogeneous than over land, need to be considered. Fluxes can thus be derived using a mass balance box-model approach. The aim of the $\mathrm{Hg}$ investigation during this experiment was to obtain more information about (1) the atmospheric $\mathrm{Hg}$ concentrations above the North Sea and (2) the processes that may affect these concentrations. 


\section{Methods and Materials}

\subsection{SAMPLING STRATEGY}

Ambient air and rainwater samples were collected for $\mathrm{Hg}$ analysis by the Free University of Brussels (VUB), Belgium on board of the R. V. BELGICA and by the GKSS Research Center Geesthacht, Germany on board of the F. S. ALKOR. The two ships were positioned on a circle with a diameter of $200 \mathrm{~km}$ of which the center was placed at $55^{\circ} 5^{\prime} \mathrm{N}$ and $4^{\circ} 0^{\prime} \mathrm{E}$ (Figure 1). The two research vessels were aligned in wind direction with the F. S. ALKOR always upwind of the R. V. BELGICA. Sampling on the R.V. BELGICA was delayed according to the calculated air mass travel time, based on the actual wind speed of the ships. A wind speed of $10 \mathrm{~m} \cdot \mathrm{s}^{-1}$ and a distance of $200 \mathrm{~km}$ resulted in a transport time of 5.5 $\mathrm{h}$ by which the downwind ship had to delay its sampling interval. Every $8 \mathrm{~h}$ new positions were taken on the circle. Forecasted trajectories were received on the F.S. Alkor up to four times a day from the UK Meteorological Office and these, together with synoptic weather charts, were used to position the ships and coordinate sampling operations. Once the position had been taken, ships moved slowly into the wind for undisturbed sampling conditions. Sampling was stopped during the travel time between positions. Samplers were installed on the top bridge of the ship, away from possible sources of contamination (chimney stacks, etc.).

Meteorological data were collected continuously throughout the whole experiment on both ships. In cooperation with the German Meteorological Service weather balloons were released twice daily from the F. S. ALKOR to provide information on upper air mass structures.

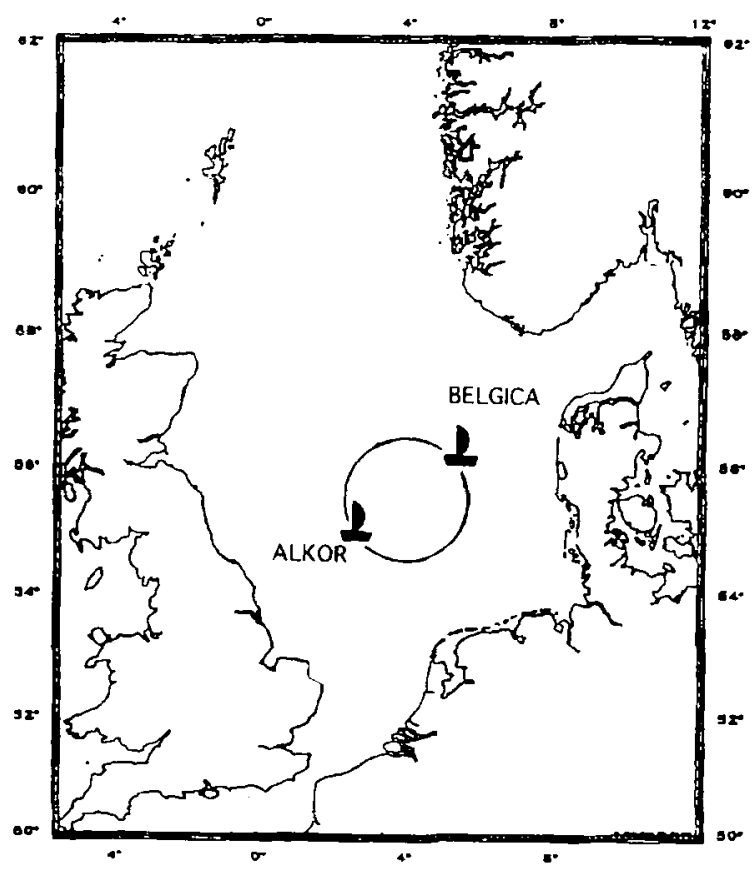

Fig 1. Position of the ships during the North Sea Experiment. September 1991 


\subsection{ANALYTICAL METHODS}

TGM was sampled by the Free University of Brussels using three gold traps placed in line. The gold traps were quartz tubes filled with $3.5 \mathrm{~cm}$ of gold coated sand. A quartz fiber filter was placed in front of the first gold column. Sampling was performed at a flow rate of $20 \mathrm{~L} /$ hour and volumes sampled ranged from 150 to $500 \mathrm{~L}$. The measurements of the gold columns were performed on board of the ship using a two stage gold amalgamation atomic fluorescence technique (Fitzgerald and Gill, 1979; Baeyens, 1992). Calibration was performed by injecting $\mathrm{Hg}$ saturated air onto the analytical column. All sampling was performed using duplicate sampling trains.

TGM was sampled by GKSS on gold coated glass beads. Two quartz tubes, $0.1 \mathrm{~cm}$ in diameter, were filled with $1.5 \mathrm{~cm}$ glass beads. A third tube filled with a gold/platinum gauze is placed between the adsorber tubes and a pump to prevent contamination. Ambient air was sucked through a $0.5 \mathrm{~cm}$ quartz wool plug before passing through the adsorber tubes. Approximately $500 \mathrm{~L}$ was air was collected with flow rates of $50 \mathrm{~L} /$ hour. To prevent contamination during storage $10 \mathrm{~g}$ of silver wool was kept in the container to bind gaseous $\mathrm{Hg}$ diffusing into the container. The analysis was carried out at GKSS using a two stage gold amalgamation atomic fluorescence technique as described above. For both laboratories the reproducibility of duplicate sampling trains is better than $5 \%$.

Rainwater was collected on an event basis. The Free University of Brussels used a $22.5 \mathrm{~cm}$ diameter PTFE funnel and thoroughly cleaned FEP bottles. After sampling the rainwater was acidified with $1 \mathrm{ml} \mathrm{HCl}$ (Merck, suprapur) $/ 100 \mathrm{ml}$ of sample. Between rain events the funnel was rinsed with Milli-Q water and stored double bagged. A funnel blank was taken between each rain event. Total $\mathrm{Hg}$ measurements were performed in the lab. The sample was oxidized with $1 \% \mathrm{BrCl}$ and analysis was performed using the cold vapor atomic fluorescence technique gold amalgamation preconcentration using $\mathrm{SnCl}_{2}$ as a reducing agent (Bloom and Crecelius, 1983).

GKSS Research Center used a $35 \mathrm{~cm}$ diameter PTFE funnel and thoroughly cleaned borosilicate glass bottles. Samples were acidified with $1 \mathrm{ml} \mathrm{HCl} / 100 \mathrm{ml}$ sample and analyzed with the same procedure as described above.

\section{Results and Discussion}

\subsection{METEOROLOGICAL CONDITIONS}

Throughout the whole experiment the prevailing winds were westerly at a wind speed of $10-15 \mathrm{~m} \cdot \mathrm{s}^{-1}$, except from September 20 to 22 and in the beginning of the experiment. Around September 20 a high pressure system developed briefly over the area with reduced wind speeds, southerly winds and reduction in the mixing height from $1000 \mathrm{~m}$ to less than $500 \mathrm{~m}$ (Figure 2, samples 12 to 15 ). This atmospheric pattern was disrupted by the passage of a front on 22 September with an associated rain event and return to westerly winds. This was the largest rain event observed with an average rainfall of $5 \mathrm{~mm}$ (samples 15 to 21 ). 


\subsection{TOTAL GASEOUS Hg}

Comparison of TGM concentrations between the F.S. ALKOR and R. V. BELGICA, together with the wind direction and wind speed is shown in Figure 2. TGM varied from 0.7 to $2.6 \mathrm{ng} \cdot \mathrm{m}^{-3}$ with an average concentration of $1.5 \mathrm{ng} \cdot \mathrm{m}^{-3}$ on the F.S. ALKOR (up-wind ship) while TGM varied from 0.7 to $1.9 \mathrm{ng} \cdot \mathrm{m}^{.3}$ with an average of 1.2 $\mathrm{ng} \cdot \mathrm{m}^{-3}$ on the R.V. BELGICA (down-wind ship). These average concentrations are lower than previously reported data for the Northern Hemisphere (Slemr, 1992; Fitzgerald et al... 1983; Schroeder, 1994) but are consistent with our measurements on the North Sea Platform and on the Island of Sylt in 1991 and 1992 (Ebinghaus et al., 1994). On two occasions concentrations lower than $\mathrm{l} \mathrm{ng} \cdot \mathrm{m}^{-3}$ were recorded on both ships (intervals 4 and 13) whereas no breakthrough of $\mathrm{Hg}$ was detected on any of the samples. The largest difference between the two ships was observed on sampling interval 18 , corresponding to the largest difference in observed wind direction between the two ships. The more southerly winds (samples 12 to 16 ) did not give rise to increased TGM concentrations.
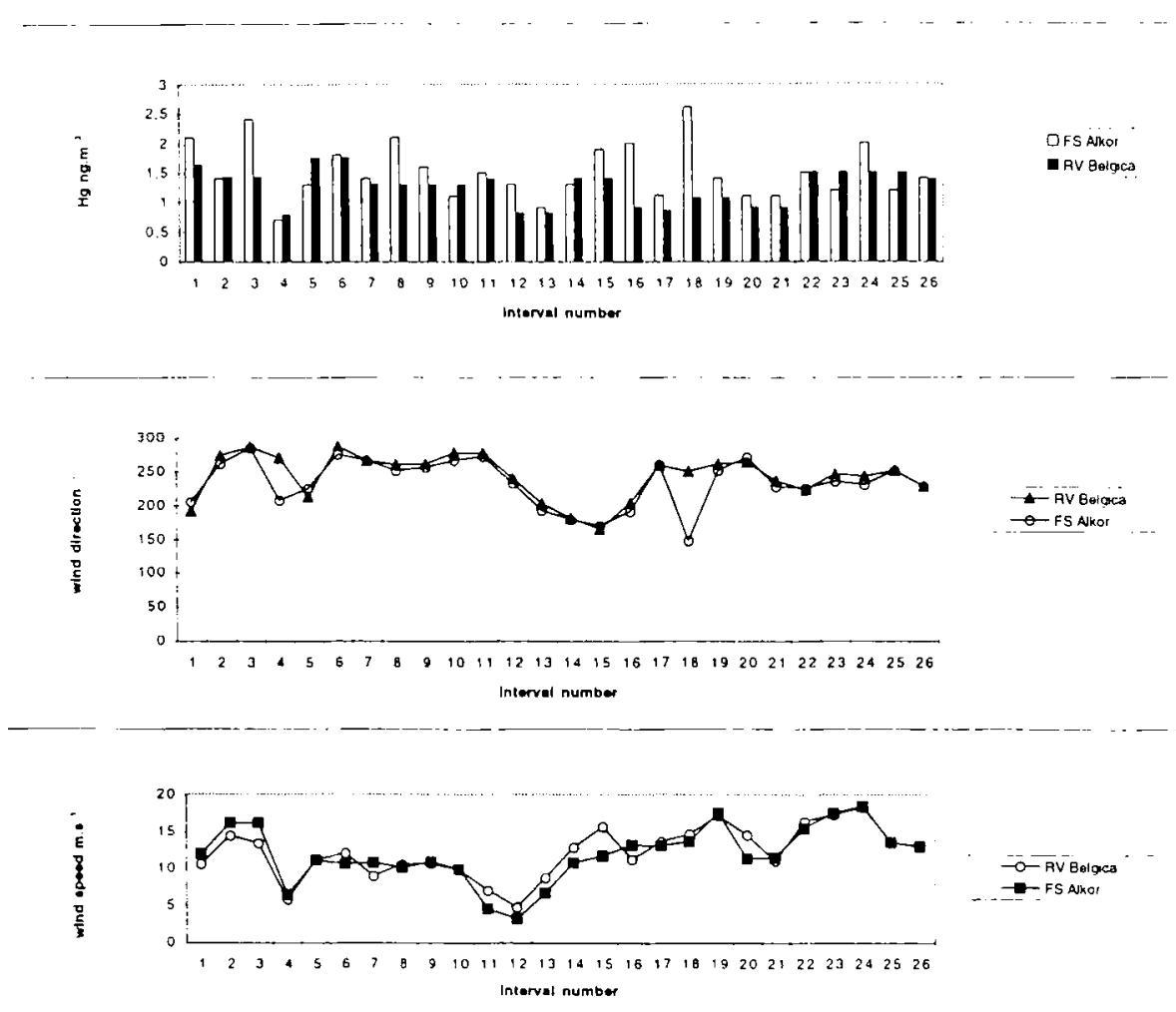

Fig 2. Total gaseous $\mathrm{Hg}$ concentrations (TGM), wind direction and wind speed measured on the F.S ALKOR (up-wind ship) and R.V. BELGICA (down-wind ship) 
An average $20 \%$ decrease in TGM from the up-wind to the down-wind ship was found. A substantial decrease in almost all trace metal concentrations on size segregated aerosols from the up-wind to down-wind ship was found (Schulz et al., 1994, Francois et al., 1992. Injuk et al., 1992) as well as a substantial decrease in concentrations of gaseous nitrogen compounds (Harrison et al., 1994, Larsen, 1994). The 30-40\% decrease which was found for anthropogenic elements, was much larger than could be expected for dry deposition alone. Important factors which may influence changes in concentrations in chemical compounds during the transport of air between the ships can arise from (1) entrainment with the free troposphere by vertical dilution, (2) chemical transformation, (3) rainfall scavenging and (4) air-sea exchange.

Entrainment in the free troposphere is probably the dominating reason for the depletion in the boundary layer. An overall removal velocity $(\mathrm{vr}=-\ln (\mathrm{Clee} / \mathrm{Cluff}) \mathrm{zi} / \Delta \mathrm{t}) \mathrm{can}$ be calculated, where Clee and Cluff are the $\mathrm{Hg}$ concentrations on down-wind and upwind ships, $\mathrm{zi}$ is the mixing layer height and $\Delta \mathrm{t}$ is the travel time of the air mass. Mixing layer heights were inferred from radiosonde data (Schulz and Larsen, 1992) and vary between 200 and $1400 \mathrm{~m}$. Calculated removal velocities varied between 0 and $5.5 \mathrm{~cm} \cdot \mathrm{s}^{-1}$ with an average of $0.95 \mathrm{~cm} \cdot \mathrm{s}^{-1}$ for the whole experiment. The average removal velocity for dry periods is 0.5 $\mathrm{cm} \cdot \mathrm{s}^{-1}$, whereas during rain events the removal velocity varies between 1 and $5 \mathrm{~cm} \cdot \mathrm{s}^{-1}$. For nitrogen species entrainment velocities were estimated to be typically 1 to $2 \mathrm{~cm} \cdot \mathrm{s}^{-1}$ and up to $5 \mathrm{~cm} \cdot \mathrm{s}^{-1}$ or more during frontal passages (Larsen, 1994). During rain events oxidation of elemental mercury and rainfall scavenging may be responsible for the increased removal rates.

Concerning air-sea exchange, surface waters of the North Sea are generally supersaturated with dissolved gaseous $\mathrm{Hg}$ (Baeyens and Leermakers, 1996, Coquery and Cossa, 1995). An average evasion flux of $0.73 \mathrm{ng} \mathrm{Hg} \mathrm{cm}^{-2} \mathrm{yr}^{-1}$ was calculated for open waters of the North Sea whereas for coastal stations this evasion flux can reach $8 \mathrm{ng} \mathrm{Hg} \mathrm{cm}$ $\mathrm{yr}^{-1}$ (Baeyens and Leermakers, 1996). The calculated evasion flux is comparable in magnitude to the wet depositional flux (see further). However, is this experiment no dissolved gaseous $\mathrm{Hg}$ measurements were made and gaseous evasion could not be detected from the atmospheric measurements as the concentrations in the down-wind ship are in most cases lower than the up-wind ship. Based on an evasion flux of $0.73 \mathrm{ng} \mathrm{Hg} \mathrm{cm} \cdot \mathrm{yr}^{-1}$ we calculated the expected increases in TGM between the F.S. ALKOR and the R.V. BELGICA for the $6 \mathrm{~h}$ time interval assuming a homogeneous concentration in the mixed layer and a mixing layer height of $1000 \mathrm{~m}$. This increase amounts to $0.003 \mathrm{ng} \cdot \mathrm{m}^{-3}$ and is thus undetectable.

$\mathrm{Hg}$ concentrations in rainwater varied from 5 to $25 \mathrm{ng} \cdot \mathrm{L}^{-1}$ and are comparable to data found in coastal and marine environments (Gill and Fitzgerald, 1987; Baeyens et al., 1991 ; Mason et al., 1992) and are consistent with our measurements on the North Sea Platform and on the Island of Sylt in 1991 and 1992. (Table I). Based on these data, wet deposition fluxes of $\mathrm{Hg}$ to the North Sea can be estimated. Using an average amount of precipitation over the North Sea of $685 \mathrm{~mm}$ (Salomons et al., 1988), the wet deposition flux of $\mathrm{Hg}$ amounts to $1.08 \mathrm{ng} \mathrm{Hg} \mathrm{cm}^{-2} \mathrm{yr}^{1 .}$. 
Table I. Hg concentrations in rainwater on the F. S. ALKOR and R. V. BELGICA

\begin{tabular}{|c|c|c|c|c|c|c|}
\hline ALKOR & & & BELGICA & & & \\
\hline \multirow[t]{2}{*}{ Date } & Time & $\frac{\mathrm{Hg}}{\left.\mathrm{ng} \cdot\right|^{-1}}$ & Date & Time & $\frac{\mathrm{Hg}}{\left.\mathrm{ng} \cdot\right|^{-1}}$ & $\frac{\text { Rainfall }}{\mathrm{mm}}$ \\
\hline & & & 16.9 .1991 & $13: 30-22: 30$ & 24.7 & 1.2 \\
\hline \multirow[t]{2}{*}{22.9 .1991} & $05: 40-09: 20$ & 24.1 & 22.9 .1991 & $02: 20-07: 45$ & 21.9 & 3.4 \\
\hline & & & $22-23.9 .1991$ & $09: 25-14: 00$ & 4.9 & 1.8 \\
\hline 24.9 .1991 & $02: 15-07: 15$ & 15.1 & $23-24.9 .199 \mid$ & $22: 00-07: 30$ & 11.9 & 1.6 \\
\hline
\end{tabular}

\section{Conclusions}

TGM was measured on board of two research vessels positioned $200 \mathrm{~km}$ apart in the center of the North Sea in September 1991. The average concentrations of TGM measured on the R.V. BELGICA $\left(1.2 \mathrm{ng} \cdot \mathrm{m}^{-3}\right)$ and on the F.S. ALKOR $\left(1.5 \mathrm{ng} \cdot \mathrm{m}^{-3}\right)$ are lower than previously reported TGM concentrations for the Northern Hemisphere. An average 20\% decrease was observed between the upwind and the downwind ship which may predominantly be due to tropospheric entrainment. An overall removal velocity of 0.95 $\mathrm{cm} \cdot \mathrm{s}^{-1}$ was calculated for the whole experiment. The average removal velocity was 0.5 $\mathrm{cm} \cdot \mathrm{s}^{-1}$ in dry periods and $>1 \mathrm{~cm} \cdot \mathrm{s}^{-1}$ during rain events. The Lagrangian experiment did not permit to detect evasion of gaseous $\mathrm{Hg}$ from the surface waters as removal of gaseous $\mathrm{Hg}$ from the boundary layer dominates. Based on the average $\mathrm{Hg}$ concentrations in rainwater of $15.8 \mathrm{ng} \cdot \mathrm{L}^{-1}$, a wet depositional flux of $\mathrm{Hg}$ to the North Sea of $1.08 \mathrm{ng} \mathrm{Hg} \mathrm{cm}{ }^{-2} \mathrm{yr}^{1 \cdot}$ was calculated.

\section{Acknowledgments}

We would like to thank Michael Schulz for coordinating the experiment, the Institute of Marine Science of Kiel, the German Weather Service. the UK Meteorological Office, the Belgian Ministry of Environment, Mathematical Modeling North Sea for their logistic support and the Belgian Science Policy Office for the financial support of the Eurotrac project.

\section{References}

Baeyens W.: 1992, Trends in Analyuical Chemistry, 11 (7), 245-254.

Baeyens W., Leermakers M., Dedeunvaerder H., Lansens P.: 1991, Water. Air and Soil Pollution, 56, 731-744.

Baeyens W. and Leermakers M.: 1996, Marine Chemistry, submitted.

Bloom N. Crecelius E.: 1983, Marine Chemistry, 14. 49-59.

Coquery M. and Cossa D: 1995. Netherlands Journal of Sea Research, 34. 4, 245-257.

Ebinghaus R., Hintelmann H., Wilken R. D... 1994, Frez. J. Anal. Chem., 350(1-2), $21-59$.

Fitzgerald W. F., Giil G. A.: 1979. Analytical Chemistr, 51 (11), 1714-1720. 
Fitzgerald W. F. Gill G. A. Hewitt A. D.: 1983, in Trace Metals in Seawater, 297-315, Wong (Ed.). Plenum Press, New York

Francois F.. Cafmeyer J., Gilot C. Maenhaut W.: 1993. Proceedings Eurotrac Symposium 1992. 788-791. P. M. Borell. P. Borell. T. Cvitas. W. Seiler (Eds). SPB Academic Publishing. The Hague

Gill G. A. Fitzgerald W. F.: 1987, Global Biogeochemeal Cycles. 1 (3), 199-212.

Harrison R.. Msibi M.. Kitto A-M., Yamulki S.: 1994. Atmospheric Environment, 28 (9). 1593-1599

Injuk J., Van Malderen H. and Van Gricken R: 1992. Eurotrac ASE Workshop. Paris

Larsen S.: 1994. Eurotrac Annual Report 1993. 3. 86-93

Lindqvist O.: 1991, Water. Air and Soil Pollution, 55.

Mason R. P., Fitzgerald W. F.. Vandal G.: 1992, J. Atmos. Chem.. 14, 489-500.

Salomons W., Bayle B.L., Duursma E.K. and Forsten U.: 1988. Pollution of the North Sea. An assessment. Springer-Verlag, Berlin.

Schroeder W.H., 1994, Mercury Pollution, Integration and Synthesis, Watras C.. Huckabee I. (Eds.). Lewis Publishers. Boca Raton

Schulz M. and Larsen S.: 1992. Unpublished report on meteorological observaions during the North Sea Experiment

Schulz M., Stahlschmidt T., Francois F., Maenhaut W. and Larsen S.: 1994, Proceedings Eurotrac Symposium. Garmisch-Partenkirchen.

Slemr F. and Langer E.: 1992, Nature, 355, 434-437 